\title{
Overview of Fishing Activities as Therapy for University Students towards Mental Wellness
}

\author{
Rugayah Hashim 1, Zaidi Mohd Aminuddin 1, Mohamad Ghazali Masuri 2, Siti Munira Yasin ${ }^{3}$ \\ ${ }^{1}$ Research \& Innovation Division, Universiti Teknologi MARA, Selangor Branch, Puncak Alam Campus, Malaysia \\ 2 Faculty of Health Sciences, Universiti Teknologi MARA, Selangor Branch, Puncak Alam Campus, Malaysia \\ ${ }^{3}$ Faculty of Medicine, Universiti Teknologi MARA, Selangor Branch, Sg. Buloh Campus, Malaysia
}

guy73106@yahoo.com, pmzaidi@yahoo.com.my, mghazali@uitm.edu.my, sitimu.yasin@gmail.com

Tel. 0133852288

\begin{abstract}
The reported increase in university students with mental health issues has resulted in the recommendation of recreational activity. Therefore, this paper provides overviews of previous studies and literature evidencing physical activities that have been effective in reducing stress levels regardless of age and gender. Fishing is the advocated activity as therapy for pre-identified students with mental health issues that have impeded their quality of life. By ensuring that there are proper, early interventions for the students, it is hoped that they will be able to handle their issues and lead a quality of life that befits the university graduate.
\end{abstract}

Keywords: mental wellness; fishing; therapy; quality of life

eISSN: 2398-4287 @ 2020. The Authors. Published for AMER ABRA cE-Bs by e-International Publishing House, Ltd., UK. This is an open access article under the CC BYNC-ND license (http://creativecommons.org/licenses/by-nc-nd/4.0). Peer-review under responsibility of AMER (Association of Malaysian Environment-Behaviour Researchers), ABRA (Association of Behavioural Researchers on Asians) and cE-Bs (Centre for Environment-Behaviour Studies), Faculty of Architecture, Planning \& Surveying, Universiti Teknologi MARA, Malaysia.

DOI: https://doi.org/10.21834/e-bpi.v5i13.2062

\subsection{Introduction}

In today's fast-paced life, media reports have shown the increment in individuals with high-stress levels leading to mental health issues. One outlet to reduce stress is to be physically active and be involved in sports. This paper provides overviews of previous studies and literature evidencing physical activities that have been effective in reducing stress levels regardless of age and gender. However, the type of physical activity should match the individual's interests and capabilities. In the case of Universiti Teknologi MARA (UiTM), Cawangan Selangor, several events have been identified in improving the issue of stress towards mental wellness among pre-identified students by organizing fishing activities as therapy at the many lakes on campus. The motivation for the event came to light after several meetings with the university's Center for Occupational Safety, Health, and Wellbeing (COSHaW). The wellness committee showcased the increment in students suffering from mental wellness problems. From the reviews, the number of university students experiencing emotional disturbances leading to an imbalance of mental health has shown a significant increase. In pursuit of a high happiness index, this problem has been a cause of concern for university administrators, where the impact of attrition for problematic students may reduce the number of graduates. In countering this issue, an empirical study must be conducted later to confirm the cause of emotional disturbance and mental health issues among university students. Nevertheless, for this paper, the methodology employed included a rigorous review of literature combined with statistical data presented at CoSHaw's meetings. The data were presented by representatives from two departments, namely the Health Center and the Counseling Division of the Student Affairs Department. Therapy fishing is advocated for students with mental challenges, unresolved emotional or behavioral issues that may be getting in the way of living a fully

eISSN: 2398-4287 @ 2020. The Authors. Published for AMER ABRA cE-Bs by e-International Publishing House, Ltd., UK. This is an open access article under the CC BYNC-ND license (http://creativecommons.org/licenses/by-nc-nd/4.0/). Peer-review under responsibility of AMER (Association of Malaysian Environment-Behaviour Researchers), ABRA (Association of Behavioural Researchers on Asians) and cE-Bs (Centre for Environment-Behaviour Studies), Faculty of Architecture, Planning \& Surveying, Universiti Teknologi MARA, Malaysia.

DOI: https://doi.org/10.21834/e-bpj.v5i13.2062 
realized life. Another significant element of this overview paper is meeting the aligned United Nation's and the university's sustainable development goals of good health and well-being. By ensuring that there are proper, early interventions for the students, it is hoped that they will be able to handle their issues and lead a quality of life that befits a university graduate.

\subsection{Background and Literature Review}

University studies are a stepping stone in life to a greater height in the future, and nonetheless, students face multiple challenges in life from various circumstances (Gall, Evans, \& Bellerose, 2000). The transition to university life requires adaptation to a different environment and may pose new workloads. (Deasy, Coughlan, Pironom, Jourdan, \& Mannix-McNamara, 2014). Furthermore, some students need jobs to fulfill their requirement needs and may come from low-income families Although students may get more freedom in their daily life, they have more responsibilities, but lack of social support and resources (Deasy et al., 2014; Gall et al., 2000).

Previous studies revealed that university students faced increasing psychological distress worldwide. Higher prevalence was reported in students from Germany (Heinen, Bullinger, \& Kocalevent, 2017), United States (Heinen et al., 2017), and Egypt (Fawzy \& Hamed, 2017). Canadian studies reported than around half had depressive symptoms and anxiety (Association, 2013), whereas places like Jordan, Spain, and the UK indicated that nurses and dental students had the highest prevalence of psychological distress. (AbuGhazaleh, Sonbol, \& Rajab, 2016; Montero-Marin, Demarzo, Stapinski, Gili, \& Garcia-Campayo, 2014). In the US, from a longitudinal study, elevated stress levels were seen among first-year college students (Gall et al., 2000; Garett, Liu, \& Young, 2017). In Malaysia, the stress and anxiety levels were as high as $33 \%$ and $11 \%$, respectively, among medical university students (Gan \& Yuen Ling, 2019).

Furthermore, university students were shown to have higher psychological stress as compared to their peers who are not studying in universities. This was shown in Australia, whereby university students showed higher levels of distress as compared to non-students of similar age group (Cvetkovski, Reavley, \& Jorm, 2012), and also higher when compared to the general population (Schacter, Guerin, \& Jacques, 2011). Factors associated with psychological stress include academic reasons (exams, assignments, practicum, assessments) (Bacchi \& Licinio, 2017), expectations either personal or social (Chemers, Hu, \& Garcia, 2001), financial reasons and living conditions (Dyrbye, Thomas, \& Shanafelt, 2006; Lo, 2002).

The effects of psychological stress are detrimental. This includes increasing mental health disorders, as reported by eight countries. (Alonso et al., 2018) with a prevalence of $31,4 \%$ in first-year students. These include anxiety (Choi, Harachi, Gillmore, \& Catalano, 2006; Saleh, Camart, \& Romo, 2017), depression (Saleh et al., 2017), suicidal ideation (Garlow et al., 2008), burnout (Maher, Brower, Mullan, Gay, \& Gruppen, 2013), suicide attempts, and self-injurious behavior (Maher et al., 2013).

Regardless of the effects of psychological distress, only a small number of students seek for medical assistance (Auerbach et al., 2016; Leahy et al., 2010). Various interventions were proposed to reduce stress, anxiety, and depression. The responses will be discussed further in this review.

\subsection{Trends on Mental Health and Wellness Among Students}

The onslaught of technology has impacted the lives of everyone, more so the younger generation. One of the popular technology gadgets that youths are addicted to is the smartphone. Immersing oneself in the smartphone has resulted in fewer movements and social interactions with dire consequences such as mental health. It has been observed in several studies that the rise in symptoms of technology, including social media, as well as the time spent, are directly correlated to poor mental health. (Lattie et al., 2019). Again, as opined by Lattie, Lipson, and Eisenberg (2019), the last several years have seen a significant increase in symptoms of depression, anxiety, eating disorders, and other mental health issues. The counselor unit and health center have also reported similar trends at Universiti Teknologi MARA, Selangor Branch, Puncak Alam Campus. Most of the students were from the social sciences cluster. However, medical students were also prone to mental health. The issue is similarly researched and reported by Shiralkar, Harris, EddinsFolensbee, and Coverdale (2013). No matter which disciplines the students are, mental wellness should be advocated by interventions such as through physical activities. Further literature evidence similar trends in mental wellness, for instance, at Australian universities. Carter, Pagliano, Francis, and Thorne (2017) reported that of 1.3 million university students in Australia, 20\% were identified to have mental health issues.

\subsection{Interventions for Mental Wellness}

From the literature reviewed, there are several accessible interventions for mental wellness. These are in the form of therapies such as retail, music, theater, dance, etcetera. Other types of intervention include digital ones. Based on the two studies identified, the first study by Ponzo et al. (2020) looked into the effectiveness of biofeedback mobile apps and wearable devices over four weeks. Results showed that the intervention was effective as compared to the control group both at two weeks and four weeks at reducing stress and depression levels. Whereas, the second study by Harrer et al. (2018) looked into the internet and apps based intervention also revealed a sustained impact of reducing depression among college students. Both papers were of good quality. Although the results used different questionnaires, both showed significant improvement in the short term and long term effects.

\subsection{Benefits of Fishing as therapy for mental wellness}

Being outdoors and participate in recreational activities be beneficial for everyone, more so those who are stressed. Fishing, as it turns out, is therapeutic for all ages (Wise, 2020). According to Wise (2020), fishing boosts self-confidence, teaches problem-solving skills, promotes clear thinking, and enhance social interaction. Aside from these, therapy fishing provide these additional benefits such as (ibid): 
- It encourages independent thought and behavior in a low-risk environment

- It creates an opportunity to take a break from daily stress

- It gives people a chance to learn a new skill or improve on their skills which can build confidence

- Regular fishing outings give people a chance to look forward to something pleasurable

- Great satisfaction in enjoying a dish from a fish caught

- Is meditative and allows for a quiet moment to self contemplate

- Appreciate the beauty of the environment and the outdoors

\subsection{Methodology}

We conducted a literature search from PubMed and Psyclnfo. According to the questions on interventions for the treatment of stress, anxiety, and depression in students, the PICO terms used were P (population, place): university or higher education students, I (interventions): any short term or long term interventions; C (comparison): comparison to usual care or other interventions and $\mathrm{O}$ (outcome): reduction or cure of symptoms of stress or anxiety or depression. The main critical individual search terms used were "Students," "Interventions," "Stress," or "Anxiety" or "Depression" Boolean operators such as "and" and "or" were also used. The time ranged from 2005-2020. References published in English provide a total of 267 total articles. After screening all abstracts, 85 abstracts were related. Twelve articles were identified as full paper that fulfilled inclusion which criteria: 1) university setting or young people; 2) It was not a thesis nor conference proceedings; 3 ) article was written in English; 4) Study design- randomized controlled trial (RCT), or cohort studies, or longitudinal studies or qualitative studies; 5) Intervention; any sorts of intervention to reduce, or change symptoms related to mental stress.

One of the authors performed the systematic search and confirmed by the other authors in the article reviewed. Any disagreement was resolved if there were any discrepancies by a third author. Items without full paper were excluded from the review. The methodological quality of the studies was also assessed based on two aspects (1) quality of the research based on less bias. An unsatisfactory evaluation means it has poor internal and external validity; (2) quality of the report assessed by the PRISMA checklist (Eskin et al., 2016). This ensures that the reviews excluded studies with poor methodology, which leaves the results ambiguous and or poor quality.

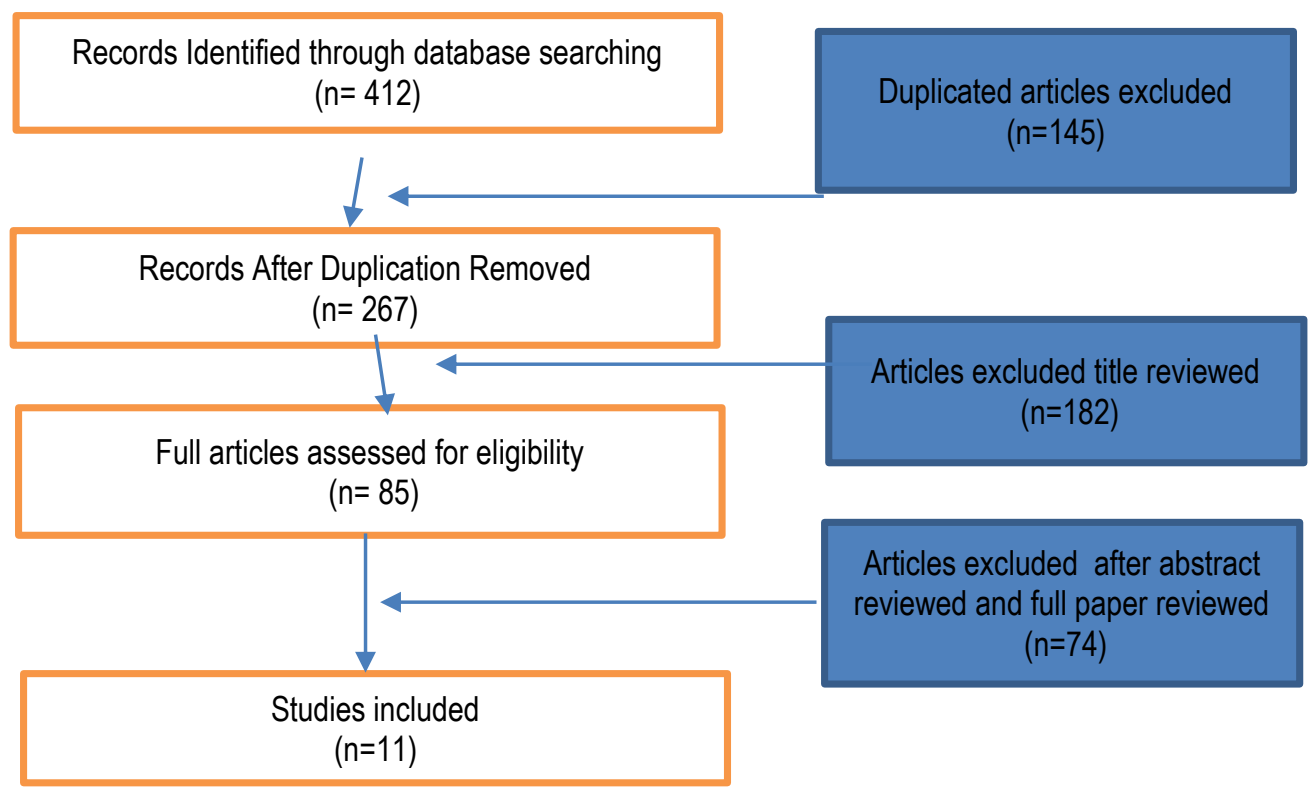

Fig. 1.0. Flow diagram of the literature search according to the items in the PRISMA guidelines.

\subsection{Results and Discussions}

The results of the reviews were divided into three main sections; digital-based intervention studies, cognitive-behavioral studies, and other interventions. Two studies were identified that looked into digital-based responses (Harrer et al., 2018; Ponzo et al., 2020), another six studies discussed on cognitive-behavioral therapies (Holm, Tyssen, Stordal, \& Haver, 2010; Pereira \& Barbosa, 2013; Pignata, Winefield, Boyd, \& Provis, 2018; Rajiah \& Saravanan, 2014; Ratanasiripong, Kaewboonchoo, Ratanasiripong, Hanklang, \& Chumchai, 2015; Wood, Ohlsen, Thompson, Hulin, \& Knowles, 2018) and three studies were in the categories of relaxation and other related 
interventions (D'Souza, Lumley, Kraft, \& Dooley, 2008; Holm et al., 2010; Kanji, White, \& Ernst, 2006). Furthermore, the overview for destressing students through a recreational activity has been beneficial, as listed in the literature review section.

To reiterate, this is an overview paper; therefore, some limitations should be acknowledged. First of all, there is no empirical evidence to support the conclusion. However, the rigorous reviews provided areas for further research that would benefit those who would like to embark on similar areas.

\subsection{Conclusion and Recommendations}

From the extensive literature reviewed, it can be concluded that students with experiencing stress and mental health issues have options and alternatives to heal. One of the ways is through therapy fishing or being active outdoors and involved in recreational activities. Mental health challenges such as depression, anxiety, and addiction are common issues that are part of life's challenges (Wise, 2020), but there are solutions to these problems. Consequently, it is recommended that for future research, empirical support is required through quantitative and qualitative approaches.

\section{Acknowledgments}

The article was published using the funds from the Fundamental Research Grant Scheme (FRGS 34/2017) awarded by the Ministry of Higher Education, Malaysia. The authors would like to acknowledge the support received from Universiti Teknologi MARA Cawangan Selangor (UCS), the Career and Counselling Center-Students Affairs Department, the Auxiliary Police Office and, the Center for Occupational Safety, Health, and Wellbeing (COShaW), Universiti Teknologi MARA Cawangan Selangor, Puncak Alam Campus, Selangor, Malaysia.

\section{References}

Abu-Ghazaleh, S. B., Sonbol, H. N., \& Rajab, L. D. (2016). A longitudinal study of psychological stress among undergraduate dental students at the University of Jordan. BMC medical education, 16(1), 90 .

Alonso, J., Mortier, P., Auerbach, R. P., Bruffaerts, R., Vilagut, G., Cuijpers, P., . . Gutiérrez-García, R. A. (2018). Severe role impairment associated with mental disorders: results of the WHO world mental health surveys international college student project. Depression and anxiety, 35(9), 802-814.

Association, A. C. H. (2013). American college health association-national college health assessment II: Reference group executive summary spring 2014. Hanover, MD: American College Health Association.

Auerbach, R. P., Alonso, J., Axinn, W. G., Cuijpers, P., Ebert, D. D., Green, J. G., . . Mortier, P. (2016). Mental disorders among college students in the World Health Organization world mental health surveys. Psychological medicine, 46(14), 2955-2970.

Bacchi, S., \& Licinio, J. (2017). Resilience and psychological distress in psychology and medical students. Academic Psychiatry, 41(2), 185-188.

Carter, M. A., Pagliano, P., Francis, A., \& Thorne, M. (2017). Australian university students and mental health: Viewpoints from the literature.

Chemers, M. M., Hu, L.-t., \& Garcia, B. F. (2001). Academic self-efficacy and first year college student performance and adjustment. Journal of Educational psychology, 93(1), 55 .

Choi, Y., Harachi, T. W., Gillmore, M. R., \& Catalano, R. F. (2006). Are multiracial adolescents at greater risk? Comparisons of rates, patterns, and correlates of substance use and violence between monoracial and multiracial adolescents. American Journal of Orthopsychiatry, 76(1), 86-97.

Cvetkovski, S., Reavley, N. J., \& Jorm, A. F. (2012). The prevalence and correlates of psychological distress in Australian tertiary students compared to their community peers. Australian \& New Zealand Journal of Psychiatry, 46(5), 457-467.

D'Souza, P. J., Lumley, M. A., Kraft, C. A., \& Dooley, J. A. (2008). Relaxation training and written emotional disclosure for tension or migraine headaches: a randomized, controlled trial. Annals of Behavioral Medicine, 36(1), 21-32.

Deasy, C., Coughlan, B., Pironom, J., Jourdan, D., \& Mannix-McNamara, P. (2014). Psychological distress and coping amongst higher education students: A mixed method enquiry. Plos one, 9(12).

Dyrbye, L. N., Thomas, M. R., \& Shanafelt, T. D. (2006). Systematic review of depression, anxiety, and other indicators of psychological distress among US and Canadian medical students. Academic medicine, 81(4), 354-373.

Eskin, M., Sun, J.-M., Abuidhail, J., Yoshimasu, K., Kujan, O., Janghorbani, M., .. Mechri, A. (2016). Suicidal behavior and psychological distress in university students: a 12-nation study. Archives of Suicide Research, 20(3), 369-388.

Fawzy, M., \& Hamed, S. A. (2017). Psychological stress among medical students in Assiut University, Egypt. Psychiatry Research, 7(2), 46-52.

Gall, T. L., Evans, D. R., \& Bellerose, S. (2000). Transition to first-year university: Patterns of change in adjustment across life domains and time. Journal of Social and Clinical Psychology, 19(4), 544-567.

Gan, G.-G., \& Yuen Ling, H. (2019). Anxiety, depression and quality of life of medical students in Malaysia. Med J Malaysia, 74(1), 57. 
Garett, R., Liu, S., \& Young, S. D. (2017). A longitudinal analysis of stress among incoming college freshmen. Journal of American college health, 65(5), 331-338.

Garlow, S. J., Rosenberg, J., Moore, J. D., Haas, A. P., Koestner, B., Hendin, H., \& Nemeroff, C. B. (2008). Depression, desperation, and suicidal ideation in college students: results from the American Foundation for Suicide Prevention College Screening Project at Emory University. Depression and anxiety, 25(6), 482-488.

Harrer, M., Adam, S. H., Fleischmann, R. J., Baumeister, H., Auerbach, R., Bruffaerts, R., . . Lehr, D. (2018). Effectiveness of an internet-and app-based intervention for college students with elevated stress: randomized controlled trial. Journal of medical Internet research, 20(4), e136.

Heinen, I., Bullinger, M., \& Kocalevent, R.-D. (2017). Perceived stress in first year medical students-associations with personal resources and emotional distress. BMC medical education, 17(1), 4

Holm, M., Tyssen, R., Stordal, K. I., \& Haver, B. (2010). Self-development groups reduce medical school stress: a controlled intervention study. BMC medical education, 10(1), 23.

Kanji, N., White, A., \& Ernst, E. (2006). Autogenic training to reduce anxiety in nursing students: randomized controlled trial. Journal of Advanced nursing, 53(6), 729-735.

Lattie, E. G., Lipson, S. K., \& Eisenberg, D. (2019). Technology and college student mental health: Challenges and opportunities. Frontiers in Psychiatry, 10(APR). doi:10.3389/fpsyt.2019.00246

Leahy, C. M., Peterson, R. F., Wilson, I. G., Newbury, J. W., Tonkin, A. L., \& Turnbull, D. (2010). Distress levels and self-reported treatment rates for medicine, law, psychology and mechanical engineering tertiary students: cross-sectional study. Australian \& New Zealand Journal of Psychiatry, 44(7), 608-615.

Lo, R. (2002). A longitudinal study of perceived level of stress, coping and self-esteem of undergraduate nursing students: an Australian case study. Journal of advanced nursing, 39(2), 119-126.

Maher, K.-H., Brower, K. J., Mullan, P. B., Gay, T., \& Gruppen, L. D. (2013). Web-streamed didactic instruction on substance use disorders compares favorably with livelecture format. Academic Psychiatry, 37(3), 165-170.

Montero-Marin, J., Demarzo, M. M. P., Stapinski, L., Gili, M., \& Garcia-Campayo, J. (2014). Perceived stress latent factors and the burnout subtypes: a structural model in dental students. PloS one, 9(6).

Pereira, M. A. D., \& Barbosa, M. A. (2013). Teaching strategies for coping with stress-the perceptions of medical students. BMC medical education, $13(1)$, 50.

Pignata, S., Winefield, A. H., Boyd, C. M., \& Provis, C. (2018). A qualitative study of HR/OHS stress interventions in Australian universities. International journal of environmental research and public health, 15(1), 103.

Ponzo, S., Morelli, D., Kawadler, J., Hemmings, N., Bird, G., \& Plans, D. (2020). Efficacy of the Digital Therapeutic Mobile App" BioBase" to Reduce Stress and Improve Mental Wellbeing Among University Students: a Randomized Controlled Trial. JMIR mHealth and uHealth.

Rajiah, K., \& Saravanan, C. (2014). The effectiveness of psychoeducation and systematic desensitization to reduce test anxiety among first-year pharmacy students American journal of pharmaceutical education, 78(9)

Ratanasiripong, P., Kaewboonchoo, O., Ratanasiripong, N., Hanklang, S., \& Chumchai, P. (2015). Biofeedback intervention for stress, anxiety, and depression among graduate students in public health nursing. Nursing research and practice, 2015.

Saleh, D., Camart, N., \& Romo, L. (2017). Predictors of stress in college students. Frontiers in psychology, 8, 19.

Schacter, D. L., Guerin, S. A., \& Jacques, P. L. S. (2011). Memory distortion: An adaptive perspective. Trends in cognitive sciences, 15(10), 467-474.

Shiralkar, M. T., Harris, T. B., Eddins-Folensbee, F. F., \& Coverdale, J. H. (2013). A systematic review of stress-management programs for medical students. Academic Psychiatry, 37(3), 158-164. doi:10.1176/appi.ap.12010003

Wise, A. (2020). Fishing Therapy: mental health benefits of fishing and being outdoors. Retrieved from gotliveeels.comfishing-therapy/

Wood, E., Ohlsen, S., Thompson, J., Hulin, J., \& Knowles, L. (2018). The feasibility of brief dog-assisted therapy on university students stress levels: the PAwS study. Journal of Mental Health, 27(3), 263-268. 